\title{
Influence of Computer Assisted Concept Mapping Instructional Strategy on Students Performance in Chemistry
}

\author{
Ibrahim Muhammad Shamsuddin, ", Ibrahim Aminu², Aminu Shamsiyya ${ }^{3}$, \\ Abubakar Mahmud Adamu ${ }^{4}$ \\ ${ }^{1}$ Science Department, Maude International Schools, Zaria, Nigeria \\ ${ }^{2}$ Science Department, Infinity School, Zaria, Nigeria \\ ${ }^{3}$ Science Department, Government Girls Secondary School, Dogon Bauchi, Zaria, Nigeria \\ ${ }^{4}$ Science Department, Government Secondary School, Kaya, Nigeria \\ Email address: \\ dheenylkhair@outlook.com (I. M. Shamsuddin) \\ ${ }^{*}$ Corresponding author
}

\section{To cite this article:}

Ibrahim Muhammad Shamsuddin, Ibrahim Aminu, Aminu Shamsiyya, Abubakar Mahmud Adamu. Influence of Computer Assisted Concept Mapping Instructional Strategy on Students Performance in Chemistry. Teacher Education and Curriculum Studies.

Vol. 2, No. 6, 2017, pp. 86-92. doi: 10.11648/j.tecs.20170206.12

Received: July 27, 2017; Accepted: August 17, 2017; Published: November 28, 2017

\begin{abstract}
This study determined the effects of Computer Assisted Concept Mapping (CACM) instructional strategies on student's performance in chemistry. It also sought the effects of CACM, on gender academic performance of students. The performance of students taught with CACM were compared with those students taught with lecture method (LM). To carry out the study, two research questions were asked and two hypotheses, were formulated and tested. A quasi experimental design involving three intact classes was used. The sample of the study consisted of 285 senior secondary one (SSI) chemistry students from three government owned secondary schools drawn using purposive and simple random sampling techniques from secondary schools in Zaria metropolis. One instrument, the Chemistry Achievement Test (CAT) was developed and validated. An internal consistency of CAT was computed and found to be 0.79 using Pearson Product Moment Correlation (PPMC). Before treatment commenced, the CAT typed in white colored paper was administered as pre-test to the students in the sampled schools. The treatment lasted for one month of five lesson periods for each group. The actual teaching was done by the regular chemistry teachers who were given special training for both experimental and control groups. After treatment session, the same instrument (CAT) which was retyped in green colored paper and the questions reshuffled was re administered to the subjects to obtain posttest scores. T-test analysis using statistical package for social sciences version 22 was used to analyze the result which shows that students taught using CACM performed better than students taught using LM. Also the results shows that CACM is gender friendly as both male and female students perform on a similar pace. It is therefore recommended that the federal government via the federal ministry of education should provide adequate ICT facilities for schools for better science achievement in the classroom. Science teachers association of Nigeria (STAN) should organize CACM seminars and workshops for science teachers and also Colleges of education should orient students' teachers towards adequate use of CACM in teaching science.
\end{abstract}

Keywords: Computer Assisted Instruction, Concept Mapping, Chemistry, Academic Performance

\section{Introduction}

The growth and development of most nations are dependent on science, technology and mathematics education. Science is that organized body of knowledge, which enhances the ability to acquire skills. It is a search for meaning or exploration of events in nature [1]. Science and technology related subjects that would enable students have a 
substantial understanding of science and be able to apply scientific knowledge in solving problems in their ever changing society are Mathematics, Physics, Biology, Health Science, Introductory technology and Chemistry.

Chemistry is one of the compulsory subjects for one to study science/ technology related courses in tertiary institutions. It is the science that deals with the properties of different atoms, the ways in which they join together to form molecules, the interaction of various kinds of molecules with one another and the accompanying energy changes. It is the heart or nucleus of science [2]. The science of chemistry includes properties, composition and structure of matter as well as structural, compositional and energy changes involved in chemical reactions. From the foregoing therefore, the major objective of teaching chemistry in our schools is to enable the students interpret the universe, since the great variety of materials in the universe can be classified into two great entities: energy and matter. Chemistry has developed knowledge in all these areas of energy and matter which will significantly help in achieving the objective of interpreting the universe [2].

The technological development of any nation lies in the study of science especially chemistry. The role of Chemistry in national development is acknowledged in the whole world [3]. The significance of chemistry in all fields of science and technology has made chemistry imperative to be included in the curriculum of senior secondary school to be offered by science oriented students. The Nigerian secondary school Chemistry curriculum has the following objectives:

(a) Facilitate a transition in the use of scientific concepts and techniques acquired in Integrated Science with Chemistry.

(b) Provide the students with basic knowledge in chemical concepts and principles through efficient selection of content and sequencing.

(c) Show Chemistry in its inter-relationship with other subjects;

(d) 12 Show Chemistry and its link with industry, everyday life, benefits and hazards;

Provide a course which is complete for students not proceeding to higher education while it is at the same time, a reasonably adequate foundation for post-secondary Chemistry courses. (FME \& CESAC, 2009p).

With the importance of chemistry and provisions made by the Federal Government of Nigeria for effective teaching and learning of chemistry, the objectives of its teaching and learning as stated in the Nigerian secondary school chemistry curriculum is yet to be achieved. Chemistry is one of the science subjects which have been taught using different methods for instance, [1] used commercially produced Computer Assisted Instructional package to teach chemistry, while Olorundare, [4] used Concept mapping and analogy to teach chemistry yet student's performance in chemistry is not encouraging. The reasons for poor performance in chemistry as identified by the following researchers include: poor instructional strategies $[5,6]$; abstract nature of science concepts [7, 8]; lack of qualified teachers [9]; poor infrastructure and inadequate laboratory facilities [10]; and non-availability and utilization of instructional materials [11]. Their findings are similar to that of Olorundare, [4] who found that inadequate laboratory facilities and nonavailability and utilization of instructional materials affect the teaching and learning of chemistry in the secondary schools. Also the chief examiner, West African Examination Council [12], identified some areas of weaknesses of the students/candidates which were reported as a contributing factor to student's poor performance. The areas identified include: Poor understanding of general principles and concepts, heat, energy changes, rates of chemical reactions, reversibility of reactions and chemical equilibrium.

The federal government of Nigeria made special provisions and incentives through the provision of laboratory facilities, instructional materials, training and retraining of teachers, provision of research grants and adoption of Information and Communication Technology (ICT) to improve the teaching and learning of science chemistry inclusive in our secondary schools. Since as part of the requirements for any school to be enrolled for WAEC and NECO is that the school must have science laboratories and with the importance of ICT in nation building, schools have been provided with computer systems through the school net programme. Furthermore, the federal government stated that "In recognition of the prominent role of information and communication technology in advancing knowledge and skills necessary for effective functioning in the modern world, there is an urgent need to integrate information and communication technology into Education in Nigeria [13]. In furtherance to government support for science education, information and communication technology is adopted by the policy to apply to all levels of education. Such provision for secondary level of education is contained in section 5 number 30. She further states that "Science shall be taught in an integrated manner in the schools to promote in the students the appreciation of basic ideas". For instance, schools in Zaria are no exceptions as government have provided the computers in almost all senior secondary schools in Zaria. Despite all the effort made by the Federal government, chemistry teachers and researchers, students perform very poorly. In order to improve the teaching and learning of chemistry the researcher is of the view that the use computer assisted concept mapping and digital video to teach chemistry may lead to better performance by the students.

Computer assisted instruction refers to instruction or remediation presented on a computer. Computer assisted instructions are interactive and can illustrate a concept through attractive animation, sound and demonstration. It allows students to progress at their own pace and work individually. Computers provide immediate feedback, letting students know whether their answer is correct or not. If the answer is not correct, it shows how the students can get the correct answer. So many researchers have used computer assisted instruction in different subject areas to improve effective teaching and learning. For instance Hall [14], examined the effect of computer assisted instruction in reading by students. Their 
findings indicated an improvement in reading when computer assisted instruction is used for students. Also Ifeakor [1] examined the effects of commercially produced computer assisted instructional package on student's achievement and interest in secondary school chemistry. In her study, she found that the commercially produced computer assisted instructional package had positive effect on the students ${ }^{\text {ee }}$ achievement and interest.

Concept maps are forms of graphical organizers which allow learners to perceive the relationships between concepts through diagramming of keywords representing those concepts. These concepts are usually enclosed in circles or boxes of some type and relationships between concepts indicated by connecting lines linking two or more concepts. The process of using these graphical tools for organizing and presenting knowledge is referred to as concept mapping. For some years now, the researches on the effectiveness of using concept mapping instructional strategy to teach chemistry has been in place. These studies includes that of Czerniak and Haney [15] who used concept mapping to improve achievement in physical sciences which includes chemistry, Nicoll, Francisco and Nakhleh [16] investigated the effect of concept mapping on general chemistry achievement. Their findings showed a positive effect. Concept mapping has been found to be a good instructional strategy used by teachers to teach chemistry yet students fail the subject, this is evident in the results of students in the WAEC and NECO, hence the researcher used computer assisted instruction which incorporates concept mapping for teaching chemistry concepts anticipating that it may improve the teaching and learning of chemistry.

Computer assisted concept mapping is an instructional strategy that incorporates the use of computer instruction with concept mapping. Not much work known to the researcher have been done using these instructional strategy to improve teaching and learning, even where it has been used, it is outside the shore of Nigeria and no study has been found for chemistry. For example, Chien-hsun $\mathrm{Tu}$ [17], conducted a study on the effect of computer assisted concept mapping learning in social studies. There was a positive effect on the studentse ${ }^{\text {ec }}$ achievement in social studies.

Historically, in most countries of the world the educational provision for boys and girls was clearly differentiated. This difference in treatment through education created and sustained gender gap, which also became visible in the science, technology and mathematics education provided. The historical background of the provision of education in Nigeria serves to give a picture of how tradition and culture has placed women and girls at a disadvantage, and restricted them to a narrow range of occupation and careers. [18], in his study on enhancing the relevance of chemistry curriculum delivery using science, technology and society (STS), stated that female students underachieve in science, technology and mathematics education relative to their male classmates. Gender has been identified as one of the factors influencing student's achievement in the sciences at senior secondary school level [7, 19]. Researchers [20, 21] have shown that males achieve higher than females in science and technology concepts. It has been noted that males perform better than females in chemistry [1]. No gender difference in student academic achievement has also been observed [22]. The contradictive evidences in academic achievement due to gender had necessitates the need to verify how computer assisted concept mapping and digital video instructional strategies can influence student's achievement in chemistry. This study therefore, examined the effects of computer assisted concept mapping and digital video instruction on students achievement in chemistry.

\subsection{Statement of the Problem}

The performance of students in science generally and chemistry in particular has been quite unsatisfactory over the years [6]. The external examining bodies such as West African Examination Council (WAEC) and National Examination Council (NECO) have repeatedly reported poor performance in chemistry.

The report of the chief examiner, West African Examination Council 2004-2005 revealed that candidate's performance was poor. For the years 2006 and 2007 the report is that there is no improvement in the performance of candidates who sat for Secondary School Certificate Examination (SSCE) in chemistry. Furthermore, a critical look at the statistics of candidatese enrolment and performance in chemistry in Nigeria between 2002 and 2007, and Candidates enrolment and performance in chemistry in Niger state for the years 2000 to 2007, shows that the performance of the candidates was poor. The percentage failure of chemistry students in the secondary school certificate examination (SSCE) for the years 2000, 2001, 2002, 2003, 2004 and 2005 are 67.42, 60.99, 53.67, 41.40, 53.28 and 46.40 respectively while the years 2006 and 2007 recorded 50.73 and 70.77 percentage failure. Also, WAEC chief examiners report for 2008-2010 indicated poor performance. In the report, 2008 recorded $77 \%$ failure, 2009 recorded $79.67 \%$ failure while 2010 recorded $80 \%$ failure. The persistent poor performance, according to the chief examiner for the years 2008- 2010 was as a result of: Poor understanding of general principles and concepts, heat, energy changes, rates of chemical reactions, reversibility of reactions and chemical equilibrium. This poor performance as indicated by the results can be attributed to many factors which includes lack of appropriate and effective use of media. This is evident from the results of the senior secondary school certificate examination for chemistry in Niger state. See appendix B. Despite all that has been done to improve students' achievement especially in chemistry, students still perform poorly. Therefore, as a result of this evident poor performance by students, the study determined the effects of computer assisted concept mapping and digital video instruction on student's achievement in chemistry.

\subsection{Purpose of the Study}

This study determined the effects of computer assisted 
concept mapping and digital video instruction on secondary school students ${ }^{\text {ee }}$ academic achievement in chemistry.

Specifically, the study determined, the

(a) Effect of computer assisted concept mapping on secondary school students' academic achievement in chemistry.

(b) Effect of computer assisted concept mapping on secondary school student's achievement in chemistry by gender.

\subsection{Significance of the Study}

Theoretically, the findings of this study will help teachers to give students task in hierarchical order. It will help teachers to move from simple to complex task. Since learning new knowledge is dependent on what is already known, curriculum planners will always consider the entry behavior of students as they plan the curriculum.

Also, it is expected that the teaching and learning process, students, teachers, teacher trainees, curriculum developers, policy makers, parents, government and the nation at large would benefit from the findings of this study in the following ways:

The result of this study will have positive impacts on teaching and learning of chemistry in secondary schools, as it will re-emphasize the need for teachers to always enrich the teaching and learning process with instructional media. This will encourage head, hand and heart co-ordination and promote harmonious interaction between learners and materials to be learnt. This in turn would relieve passivity, monotony, excessive verbalism, thereby preventing chemistry from being taught in a manner that produces in the mind of learners a feeling of boredom and distaste for chemistry.

The results of this study is expected to be useful to the learners as it will provide opportunities for students to practice basic skills, learn some basic concepts on their own and at their own pace. Also it can lead to arousing students interest in science especially chemistry, make them to be creative and help in the generation of ideas to solve world problems. By the use of digital video instructional package, the interest of the learners for irrelevant movies and entertainment programs could systematically be transferred to a more productive and educative pursuit. Also the learners listening skill which is vital to efficient learning would be improved upon.

Since students learn differently and at different pace, abstract concepts are simplified and individualized learning will be encouraged. The result will encourage teachers to use multiple media in presenting instructions to students. It will also help teachers to vary their instructional approaches, develop creative skills and help in making their lesson interesting as well as making their instructional objectives to be achieved.

The findings could hopefully assist curriculum planners to include in the curriculum for secondary level instructional materials/strategies that would help in bringing about meaningful learning. It may also provide locally produced computer instructional package, the use of which would consequently build up teacher's and learners confidence in the subject matter and to be information and communication technology (ICT) compliant. This is to give direction and confidence to the teacher whose job it is to put the curriculum into use and to ensure the attainment of specific objectives of learning science.

The findings of this study would be of immense benefit to the nation as it could lead to the turnout of learners with solid foundation in science (chemistry) to meet the demands of science and technology of the new millennium. This study may be a spring board for future researchers who might wish to embark on a similar study in chemistry or other discipline such as biology or physics.

\subsection{Scope of the Study}

This research examined the effects of computer assisted concept mapping on the academic achievement of students in chemistry. Zaria metropolis was used and three schools were covered. Two schools served as the experimental while the remaining one served as the control. The study was limited to Senior Secondary I $\left(\mathrm{SS}^{\mathrm{I}}\right)$ of the Senior Secondary Schools selected in Zaria Metropolis. The topics or subject matter covered are Atomic Theory, element Compound and mixture and kinetic theory of gases.

\subsection{Research Questions}

The study was guided by the following questions

(a) What is the effect of computer assisted concept mapping instructional strategy on secondary school student's achievement in chemistry?

(b) What is the influence of gender on secondary school student's achievement in chemistry using computer assisted concept mapping instructional strategy?

\subsection{Research Hypotheses}

The following research hypotheses were formulated.

$\mathrm{HO}_{1}$ : There is no significant difference between the mean achievement scores of students taught chemistry using computer assisted concept mapping instructional strategy and lecture method.

$\mathrm{HO}_{2}$ : There is no significant difference in the mean achievement scores of male and female students taught chemistry using computer assisted concept mapping instructional strategy.

\section{Research Methodology}

The research design adopted for this study is quasiexperimental design, focusing on influence of computer assisted instructional strategy on academic performance of chemistry students in some selected secondary schools in Sabon Gari Local Government Area of Kaduna State. The population of this research work constitutes some selected secondary schools in Sabon Gari Local Government Area of Kaduna state. The selected schools are a total of three (3) 
senior secondary school with a total population of one thousand and ninety six (1096) students. A total of 285 respondents from all the three (3) selected senior secondary schools in Sabon Gari Local Government Area were used in the study. Sample size was chosen in line with Krejcie and Morgan, [23] sample size table. This is to make sure all students are duly represented in the study. Simple random sampling will be used to select the targeted number of respondents from all schools to represents the sample for study. The main instrument for data collection in this study is a researcher designed assessment test titled Chemistry Achievement Test (CAT). The first section (Section A) contains the general information such as of sex, age, class and name of school. Section B constitute of twenty (20) questions on atomic theory, element, compound and mixture and kinetic theory of gases. The researcher visited the sampled schools to teach the students using lecture method and then administer the test to the respondents/students. Thus after a week time interval the teacher visited the schools again and teach the students using the computer assisted instructional strategy, and also after the class administer same test to the students. The respondents were in their various classes, with the help of their teachers the researcher administered the test to them. Validation is the process of ensuring the degree of effectiveness of each of the items in the research instrument. It is the process of determining the extent to which each of the items measures what it is designed to measure [24]. The validity of an instrument is always determined by an expert opinion and vetting comprising of experts in the field of education attesting to its relevance and appropriateness in the testing of the study. Therefore, the Chemistry Achievement Test (CAT) was validated by science education experts. Reliability is necessary to ascertain whether the instruments are capable of reproducing consistent or similar results after a number of repeated administrations. Split half reliability tests was carried out with a reliability coefficient of 0.79 using Pearson Product Moment Correlation (PPMC) which determined that the measuring instruments is consistent and reproducible. Data analysis is the process of systematically applying statistical and/or logical techniques to describe and illustrate, condense and recap, and evaluate data. Therefore, in this research work, the researcher will use the statistical package for Social Science (SPSS, version 22) as a statistical tool for data analysis.

\section{Results and Discussion}

In order to answer the first research question which sought to establish if computer assisted concept mapping instructional strategy has influence on secondary school student's achievement in chemistry in the study area and the null hypothesis which says; There is no significant difference between the mean achievement scores of students taught chemistry using computer assisted concept mapping instructional strategy and lecture method. The collected data was subjected to t- test analysis using Statistical Package for social science version 22 (SPSS), the results obtained were presented in table 1.

Table 1. T- test Analysis of the Test Mean Performance of the Students Taught by Lecture Method (LM) and those taught using Computer Assisted Concept Mapping (CACM).

\begin{tabular}{lllllllll}
\hline Variable & N & X & S. D & S. E & Df & t- value & P & Remarks \\
\hline LM & 285 & 5.06 & 1.179 & 0.070 & 284 & 72.368 & 0.000 & Sign. \\
CACM & 285 & 8.43 & 1.340 & 0.079 & 284 & 106.199 & & \\
\hline
\end{tabular}

Significant @ P $\leq 0.05$

The results obtained from table one shows that there is significant difference between the mean achievement scores of students taught chemistry using computer assisted concept mapping instructional strategy and lecture method since an alpha level of significance was found to be 0.00 which is less the Significant of $\mathrm{P} \leq 0.05$. Therefore, the null hypothesis is rejected and the alternative hypothesis which says there is significant difference between the mean achievement scores of students taught chemistry using computer assisted concept mapping instructional strategy and lecture method is hereby accepted. The findings of this study revealed that the use of computer assisted concept mapping learning strategy had a significant effect on students ${ }^{\text {ee }}$ achievement in chemistry. The students taught using computer assisted concept mapping achieved significant better than those taught using lecture method. This result is in agreement with the result of Seng [25]. They found out that computer assisted concept mapping enhanced students achievement in chemistry. Tenth grade students in Singapore were treated with computer assisted concept mapping and the students in these group performed significantly better than those without computer assisted concept mapping. This result is also in agreement with Lou, Wen and Tseng [26], who investigated the effect of integrating concept mapping into computer assisted instruction in chemistry learning achievement. Their findings revealed that the students in the experimental group who were treated with computer assisted concept mapping achieved significantly better than those in the control group. The trend of higher performance by the treatment (CACM) group could be as a result of self - evaluation and remedial activities provided by (CACM) which helped students to master the chemistry concepts without much difficulty than the (LM) group.

The data obtained in the table above shows that there is no significant difference in the performance of male and female students taught using computer assisted concept mapping. Since an alpha level of significance of 0.064 was found, thus the Null hypothesis which says; there is no significant difference in the mean achievement scores of male and female students taught chemistry using computer assisted 
concept mapping instructional strategy is thereby retained this contradicts Shashaani [27] who carried out a study on gender-based differences in attitudes of secondary schools students toward computers. Approximately 1750 ninth and twelfth grade students from five different school districts in Pittsburgh, Pennslvania, participated in the survey. A significant sex difference in attitudes towards computers was observed.

Table 2. T- test Analysis of the Test Mean Performance of the Students Taught Using Computer Assisted Concept Mapping by Gender.

\begin{tabular}{llllllll}
\hline Variable & N & X & S. D & S. E & Df & t- value & P \\
\hline Male & 150 & 7.19 & 3.824 & 0.312 & 149 & 23.018 \\
Female & 135 & 6.30 & 2.881 & 0.248 & 134 & 25.419 \\
\hline
\end{tabular}

Significant@ $\mathrm{P} \leq 0.05$

\section{Conclusion}

The study had shown that CACM had significant effects on the student's academic achievement in chemistry. The CACM appeared to be outstandingly more effective than the LM. The study revealed that CACM is efficient in producing high academic achievement in chemistry. This would suggest then that the use of CACM in chemistry teaching will enhance student's achievement. Inadequate supply of human resources, especially technical support systems makes innovative practices difficult. These innovations like CACM, demand well trained personnel, and this makes training and retraining of staff imperative. The influence of gender on academic achievement in chemistry was not significant when CACM is applied.

\section{Recommendations}

In view of the findings of this study the following recommendations were made;

i. The federal government via the federal ministry of education should provide adequate ICT facilities for schools for better science achievement in the classroom.

ii. Science teachers association of Nigeria (STAN) should organize CACM seminars and workshops for science teachers

iii. Colleges of education should orient student teachers towards adequate use of CACM in teaching science.

\section{References}

[1] Ifeakor (2006: The Status of Resources for Effective Teaching of Chemistry in Nigerian Secondary Schools. STAN proceedings $200647^{\text {th }}$ Annual Conference.

[2] Adeniyi, A. (1997). Computer Aided instruction and achievement in Physics. Innovations in Science, Technology and Mathematics. STAN proceedings of Ajumogobia Memorial Conference. Pp 257-260.

[3] Udofie, T. M. and Udo M. E. (2006): Plantdyes A Resources for effective Teaching and Learning of Trimetric Analysis in Chemistry. STAN Proceeding Annual Conference.

[4] Olorundare, S. A. (2009). Comparative effects of Concept Mapping, Analogy and Expository Strategies on Secondary
School Students Performance in Chemistry in Ilesa, Nigeria. Journal of Curriculum and Instruction, $7(1 \& 2)$.

[5] Bajah, S. T. (2000). The state of science, technology and mathematics education in Nigeria. UNESCO, (925), 3-4.

[6] Olorukooba, S. B. (2007). Science, technology and mathematics (STM) education is for all students: Promoting effective teaching of STM subjects in our schools through teacher preparation. Proceedings of the $50^{\text {th }}$ Anniversary Conference of Science Teachers Association of Nigeria. Pp 36.

[7] Nsofor, C. C. (2006) Assessing the Effects of Designed instructional model on Studentse ${ }^{\text {ee }}$ Performance in Science. $2^{\text {nd }}$ School of Science and Science Education Conference FUT, Minna 391-398.

[8] Ojiaku, F. C. (2003). The effects of combining advance organizers, video package and lecture method on students achievement in integrated science in Oshodi local government area of Lagos State. Unpublished M. Tech thesis, Federal Univeersity of Technology, Minna.

[9] Biodun, K. (2004). A Comparative Study of the effect of teacher qualification and teaching method on students achievement in Chemistry. Unpublished Ph.D thesis. University of Calabar.

[10] Shawl, A. (2003). An adoption of problem-based teaching and problem-based learning to improving the teaching of radioactivity. Chinese Journal of elementary Science 3(1), 1418.

[11] Yusuf, A. (2004). Effects of cooperative and competitive instructional strategies on junior secondary school students performance in social studies, in Ilorin, Nigeria. Unpublished Ph.D Thesis, curriculum Studies and Educational Technology, University of Ilorin, Nigeria.

[12] West African Examination Council (2007) Annual Report.

[13] NITDA (2003) National Information Technology and Development Agency Project. Retrieved 12 July, 2007 from http://www.nitda.org.

[14] Hall, E. R, Mclaughlin, T. F., and Bialozor, R. C. (1989). The Effects of Computer-Assisted Drill and Practice on Spelling Performance with Mildly Handicapped Students. Reading Improvement 26(1), 43-49.

[15] Czerniak and Haney, (1998). Effect of concept mapping on student achievement in physical sciences courses

[16] Nicoll, G., Grancise D. J. S. and Nakhleh, M. (2001). An Investigation of the Value of using Concept Maps in General Chemistry. Journal of chemical Education, 78 (8), 11111117. 
[17] Chien-hsun, T. (2006). A study on integrating Information Technology into Instruction and Computer-Assisted Concept learning in Social Studies Retrieved on 26/5/2009.

[18] Njoku, Z. C. (2009). Enhancing the Relevance of Chemistry Curriculum Delivery using Science Technology-Society (STS) Approach. International Council of Associations for Science Education.

[19] Nsofor, C. C. (2006) Assessing the Effects of Designed instructional model on Studentse Performance in Science. $2^{\text {nd }}$ School of Science and Science Education Conference FUT, Minna 391-398.

[20] Ifamuyiwa, A. S. (2004). The predictive validity of junior secondary Mathematics on Senior Secondary Mathematics, further Mathematics and Physics. STAN 45 Annual Conference Proceedings.

[21] Iwendi, B. C. (2009). The Influence of gender and age on the Mathematics Achievement of Secondary School Students in Minna Metropolis, Niger State. Unpublished M. Tech. Thesis, Science Education Dept. FUT, Minna, Nigeria.

[22] Yusuf, M. O. and Afolabi, A. O. (2010). Effects of computer assisted instruction (CAI) on secondary school students performance in Biology. The Turkish online journal of Educational Technology; Volume 9,(1).

[23] Krejcie, Robert., Morgan, Daryle, W. "Determining Sampling Size for Research Activities", Educational and Psychological Measurement, 1970.

[24] Jibril, M. (2000). Annual Report: Security unit. Abuja: National Universities commission

[25] Seng, C. Y. (2000): The effects of incorporating concept mapping into Computer Assisted Instruction. Baywood Publishing Company Inc.

[26] Lou, S., Wen, H. and Tseng, K. (2007). A study Of Integrating Concept Mapping intoComputers Assisted Instruction in Chemistry Learning Achievement and learning Attitude at a comprehensive High Schools: Chinese Journal of Science Education Vol. 15 (2) Pg 69-194.

[27] Shashaani, L. (1993). Gender-based differences in attitudes towards computer. Computer and Education 20(2), 169-181. Retrieved $12^{\text {th }} \quad$ April, 2007 from http://www.sciencedirect.com/sceince?_ob=ArticleURL\&_udi $=\mathrm{B} 6 \mathrm{VCJ} 469 \mathrm{PHF} 8$ 